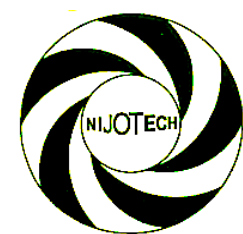

Nigerian Journal of Technology (NIJOTECH)

Vol. 37, No. 2, April 2018, pp. 358 - 364

Copyright@ Faculty of Engineering, University of Nigeria, Nsukka,

Print ISSN: 0331-8443, Electronic ISSN: 2467-8821 www.nijotech.com

http://dx.doi.org/10.4314/njt.v37i2.10

\title{
ASSESSING THE PERFORMANCE OF GLOBAL SOLAR RADIATION EMPIRICAL EQUATIONS IN SOKOTO, NIGERIA USING METEOROLOGICAL PARAMETERS
}

\author{
M. B. Garba ${ }^{1}$, A. Muhammad ${ }^{2,}{ }^{*}$, M. Musa ${ }^{3}$ and A. G. Mohammed \\ 1,2, Department of Physics, Kano University of Science and Technology, Wudil, Kano State nigeria \\ 3, Department of Physics, Nigerian Police Academy, Wudil, P. M. B. 3474, Kano - Kano State Nigeria \\ 4, DEPARTMENT OF MATERIAL SCIENCE, ERCIYES UNIVERSITY, KAYSERI- TURKEY \\ E-mail addresses: ${ }^{1}$ bmustapha2011@yahoo.com, ${ }^{2}$ auwalsafa@gmail.com, ${ }^{3}$ musamunzali@yahoo.com, \\ 4 agmaisalati@gmail.com
}

\begin{abstract}
In this study, the meteorological parameters measured in Sokoto $\left(12.55^{\circ} \mathrm{N}, 5.15^{\circ} \mathrm{E}\right)$ for a period of 10 years (20052014) were obtained from the Nigerian Meteorological Agency Sultan Abubakar III International Airport, Sokoto state. The data used include Gunn-Bellani solar radiation, sunshine hour duration, maximum and minimum temperatures, which were analyzed using modified Angstrom models to estimate the monthly mean global solar radiation in Sokoto. Four statistical methods have been used in order to evaluate the results namely; Mean Bias Error (MBE), Mean Percentage Error (MPE), Root Mean Square Error (RMSE) and T-statistic. The standard error (SE) and coefficient of determination $\left(R^{2}\right)$ were also obtained for each model. Based on the result obtained models 4 \& 5 gave a lower RMSE, and $R^{2}$ approaches unity, which indicates that there is a good agreement between measured and estimated global solar radiation.
\end{abstract}

Keywords: coefficient of determination, solar radiation, sunshine hours, meteorological parameters, temperature

\section{INTRODUCTION}

Renewable energy is meditated to be the most significant source in the world in the near future. The decrease in the fossil fuels made an orientation to the renewable-energy sources such as sunlight, the wind, rain, tides, and geothermal heat. Renewable energy is a substitute for fossil fuels and nuclear power and was generally called alternative energy in the 1970s and 1980s [1].

However, many third-world countries like Nigeria cannot boast of the one-week uninterrupted power supply. The need for solar radiation data becomes inevitable. The knowledge of the available solar radiation at a place is essential in selecting and designing suitable solar-energy systems for that location. Unfortunately, for many developing countries like Nigeria, solar radiation measurement's equipment is not widely available due to the high cost of the required equipment, and the techniques involved. Only in a few designated locations like airports and some meteorological stations are solar radiation data available. It is therefore, important to establish theoretical models to estimate the global solar radiation and its components using well established climatological data such as temperature, relative humidity, sunshine hours, rainfall, etc. [1].

The first attempt to estimate global solar radiation was due to Angstrom. The original Angstrom-type regression equation relates monthly average daily solar radiation to clear day radiation at the location and average fraction of possible sunshine hours [2]. The equation is given as simple linear relation to the form.

$$
\frac{\bar{H}}{\overline{H_{C}}}=a^{\prime}+b^{\prime} \overline{\bar{N}}
$$

where $\bar{H}=$ monthly average daily radiation on a horizontal surface, $\quad \bar{H}_{c}=$ average clear sky daily radiation for location and month, $\mathrm{a}^{\prime}$ and $\mathrm{b}^{\prime}=$ empirical constants, $\bar{n}=$ monthly average daily hours of bright sunshine, $\bar{N}=$ monthly average of maximum possible daily hours of bright sunshine. A basic difficulty with the equation lies in the ambiguity of the terms $\frac{\bar{n}}{\bar{N}}$ and $\bar{H}_{c}$. Page in 1964 and others have modified the method to base it on extraterrestrial radiation on a horizontal surface rather than on clear-day radiation: 


$$
\frac{\bar{H}}{\overline{H_{\circ}}}=a+b \frac{\bar{n}}{\bar{N}}
$$

where $\overline{H_{\circ}}$ is the extraterrestrial radiation for the location and $\mathrm{a}$ and $\mathrm{b}$ are constant depending on the location. The ratio $\frac{\bar{H}}{\overline{H_{\circ}}}$ is termed the monthly average clearness index.

Because of lack of reliable solar radiation, several efforts have been made by many researchers to develop or modify the original Angstrom model to estimate the number of solar radiations from other meteorological data at a different location around the world. Among these are: Auwal and Darma [3] proposed two new models for estimating monthly global solar radiation for Kano State. The temperaturebased model gave a better result in comparison to relative humidity based model, Okonkwo and Nwokoye [4] developed thirteen different models using meteorological parameters which include sunshine hours duration, relative humidity, rainfall, wind speed, maximum and minimum temperature. The data were analyzed using both single variable and multi-variable regression equations for Bida, Niger State. Results showed that, the multivariable model which comprises sunshine hours, maximum and minimum temperature fits well with measured solar radiation, El-Sebaii, [5], Aliyu and Sambo [6] evaluated the accuracy of five existing theoretical models for prediction global solar radiation in Sokoto that use maximum/minimum temperature and relative humidity as input parameters. The results shows a mismatch between the value obtained using sayigh equation and those obtained from different models, Salima and Chavula [7], Almorox, et.al [8] calibrated seven existing solar models and developed one new model for predicting global solar radiation data based on temperature data measured at seven different stations located in Madrid, Spain. Their results showed that the empirical models based on temperature gave better predictions at any location if their coefficient were correctly adjusted. In addition, the newly suggested models gave the best estimation for all stations, Almostafa et. al [9] reported the performance of fifty-two sunshine based models to estimate monthly average global solar radiation in Saudi Arabia. The results shows that some models are not accepted for use in the region and others vary in their performance, Tog̃rul and Tog̃rul [10] developed various regression equations for estimating monthly global solar radiation in Turkey by using $\frac{\bar{n}}{\bar{N}}$ and $\frac{\bar{n}}{\bar{N}_{n h}}$ parameters. Results obtained shows that equations developed by using $\frac{\bar{n}}{\bar{N}_{n h}}$ ratio showed good results for the whole Country, but those which include $\frac{\bar{n}}{\bar{N}}$ ratio at different cities showed better results.

As of today, fossil fuels are the major energy sources that are being used. However, there over- consumption leads to serious environmental issues such as air pollution. Therefore, knowledge of solar radiation data will provide the means of assessing the viability of utilization of solar energy in Sokoto state as a renewable-energy alternative.

In this study, two sunshine hour's based models and three temperature based, models were developed to estimate monthly global solar radiation on horizontal surfaces in Sokoto state, Nigeria, using monthly mean daily minimum/maximum temperatures and sunshine hour's duration. Five different models are proposed for estimating monthly global solar radiation, two models are introduced in this study as new models and three models were previously developed and used in the literature. The performance of the new suggested models and the existing models is compared against the measure data of global solar radiation in Sokoto State.

The objective of this work is to estimate the global solar radiation of Sokoto state using modified Angstrom model and meteorological data and to compare all the models by using regression analysis.

\section{MATERIALS AND METHODS}

In this present study, data of the monthly mean global solar radiation, sunshine duration, maximum and minimum temperature for a period of 10 years (20052014) for Sokoto Northwestern Nigeria, with latitude of $12.55^{\circ} \mathrm{N}$ and longitude of $5.150^{\circ} \mathrm{E}$ were obtained from Nigerian Meteorological Agency, Sultan Abubakar III International Airport Sokoto, Sokoto State. The data obtained were used for the analysis. The original data for global solar radiation was measured using GunnBellani Pyrometer. The data was recorded in MILLILANGLY, where $1 \mathrm{~mL}=4.184 \times 10^{-3} \mathrm{~J} / \mathrm{cm}^{2} \mathrm{sec}$. It was then converted to $\mathrm{MJ} / \mathrm{m}^{2}$ day i.e.

Solar Radiation in $\mathrm{MJ} / \mathrm{m}^{2}$ days =

$$
\begin{gathered}
\text { (Solar radiation in } \mathrm{mL}) \times 41.84 \frac{\mathrm{MJ}}{\mathrm{m}^{2} \mathrm{sec}} \times 3600 \text { secs } \\
\times(\text { Monthly mean Sunshine hours }) \\
\times 10^{-6}[11] .
\end{gathered}
$$

The monthly average daily extraterrestrial radiation on a horizontal surface $\overline{\mathrm{H}}_{0}$ can be computed from the following equation [2]. 


$$
\begin{aligned}
\overline{\mathrm{H}}_{0}=\frac{24 \times 3600 G_{S C}}{\pi} & \left(1+0.033 \cos \frac{360 n}{365}\right) \\
& \times\left(\cos \emptyset \cos \delta \sin w_{s}\right. \\
& \left.+\frac{\pi w_{s}}{180} \sin \emptyset \sin \delta\right)
\end{aligned}
$$

Solar declination angle $\delta$, Sunset hour angle $w_{s}$, and length of the day $\overline{\mathrm{N}}$ are expressd as [2];

$$
\begin{aligned}
\delta & =23.45 \sin \left[\frac{360}{365}(284+d)\right] \\
\mathrm{W}_{\mathrm{s}} & =\cos ^{-1}(-\tan \emptyset \tan \delta) \\
\overline{\mathrm{N}} & =\frac{2}{15} \cos ^{-1}(-\tan \emptyset \tan \delta)
\end{aligned}
$$

This work was focused on the use of the modified Angstrom-Prescott model in the estimation of the monthly mean global solar radiation the equations used for the study are of the form indicated in the equations below:

\subsection{Temperature Based Model}

Equations (8) and (9) are the proposed models used in this paper:

$$
\begin{aligned}
& \frac{H}{H_{0}}=a+b\left(\frac{T_{\max }-T_{\min }}{T_{\max }}\right) \\
& \frac{H}{H_{0}}=a+b\left(\frac{T_{\max }-T_{\min }}{T_{\max }}\right)^{\frac{1}{2}} \\
& \frac{H}{H_{0}}=a+b\left(\frac{T_{\min }}{T_{\max }}\right)
\end{aligned}
$$

\subsection{Sunshine Hour's Based Model}

$$
\begin{aligned}
\frac{\mathrm{H}}{\mathrm{H}_{\mathrm{o}}} & =\mathrm{a}+\mathrm{b}\left(\frac{\overline{\mathrm{n}}}{\overline{\mathrm{N}}}\right) \\
\frac{\mathrm{H}}{\mathrm{H}_{0}} & =\mathrm{a} \cos \emptyset+\mathrm{b} \frac{\mathrm{n}}{\mathrm{N}}
\end{aligned}
$$

These are the linear models, which include: The actual Angstrom-Prescott model (That is commonly adopted model) and different modified Angstrom models, which have not been used to predict the global solar radiation in Sokoto state, Nigeria.

\section{The Model Performance Estimation}

The correctness of the estimated values of the global solar radiation was tested by calculating the Mean Bias Error (MBE), Root Mean Square Error (RMSE), Mean Percentage Error (MPE), and t-Statistic Method [12].

$$
\begin{gathered}
\text { MBE }=\sum_{\mathrm{k}=0}^{\mathrm{n}}\left(\mathrm{H}_{\mathrm{est}}-\mathrm{H}_{\text {meas }}\right) / \mathrm{k} \\
R M S E=\sqrt{\frac{\sum_{\boldsymbol{k}=\mathbf{0}}^{n}\left(\boldsymbol{H}_{\text {est }}-\boldsymbol{H}_{\text {meas }}\right)^{2}}{k}} \\
M P E=\left(\sum \frac{H_{\text {meas }}-H_{\text {est }}}{H_{\text {meas }}}\right) \times \frac{100 \%}{k}
\end{gathered}
$$

$$
t-\text { statistic }=\sqrt{\frac{(k-1) M B E^{2}}{R M S E^{2}-M B E^{2}}}
$$

$\mathrm{K}$ stand on the number of observation that is in this study it means a number of month for a year, while $\mathrm{H}_{\text {est }}$ and $\mathrm{H}_{\text {meas }}$ are the estimated and the measured mean daily global solar radiation respectively. In general, a low RMSE is desirable, a positive MBE show overestimation while a negative MBE indicates underestimation [13].

\section{RESULTS}

The monthly mean extraterrestrial radiations on a horizontal surface for Sokoto state were calculated by the used of the following parameters, i.e. declination angle, latitude and sunset hour angle using Equation (4). The declination angle and sunset hour angle were calculated using equation (5) and (6) respectively.

The regression constants $\mathrm{a}$ and $\mathrm{b}$ were obtained using Microsoft Excel 2013, and the values were substituted in equation (8) to (12) respectively.

Table 1: Regression equations and their constants. Temperature based Models

$1 \quad \frac{H}{H_{0}}=1.78-1.86\left(\frac{T_{\min }}{T_{\max }}\right)$

$2 \frac{H}{H_{0}}=-0.081+1.86\left(\frac{T_{\max }-T_{\min }}{T_{\max }}\right)$

$3 \quad \frac{H}{H_{0}}=-0.77+2.28\left(\frac{T_{\max }-T_{\min }}{T_{\max }}\right)^{\frac{1}{2}}$

Sunshine's Hours Based Models

$4 \frac{\mathrm{H}}{\mathrm{H}_{\mathrm{o}}}=-0.4906+1.6482\left(\frac{\overline{\overline{\mathrm{n}}}}{\overline{\mathrm{N}}}\right)$

$5 \frac{\mathrm{H}}{\mathrm{H}_{0}}=-0.4906 \cos \varnothing+1.6482 \frac{\mathrm{n}}{\mathrm{N}}$

Table 2 shows the error test results of the developed models. It is observed that model 4 yielded the lowest MBE MPE and RMSE values followed by model 5 which also has a low RMSE and has the highest value of MBE, followed by model 1, 2 and 3. It is also observed that models 4 and 5 have the highest $\mathrm{R}^{2}$ value which fit well with the measured data.

\subsection{Comparison Techniques for Measured and Predicted Global Solar Radiation}

The measured and predicted global solar radiation for sunshine hour's based models and temperature-based models were merged together in graphs to compare and assess the best model for prediction of monthly mean average global solar radiation for the locations of 
the study. However, the graphs for each model were plotted in order to see the relation between measured and estimated data and as well as to determine the monthly mean global solar radiation in the period of study.

Table 2: Statistical Indicator of the Models

\begin{tabular}{ccccccc}
\hline Models & SE & $\mathrm{R}^{2}$ & MBE & MPE & RMSE & T-statistic \\
\hline 1 & 0.16 & 0.837 & 0.0079 & 2.027 & 2.2254 & 0.0119 \\
2 & 0.09 & 0.837 & 0.0080 & 2.027 & 2.2254 & 0.0119 \\
3 & 0.18 & 0.856 & 0.0047 & 1.801 & 2.0851 & 0.0074 \\
4 & 0.07 & 1.000 & -0.0088 & 0.4623 & 1.1047 & 0.0267 \\
5 & 0.05 & 0.962 & 0.4042 & 2.608 & 1.1746 & 1.2157 \\
\hline
\end{tabular}

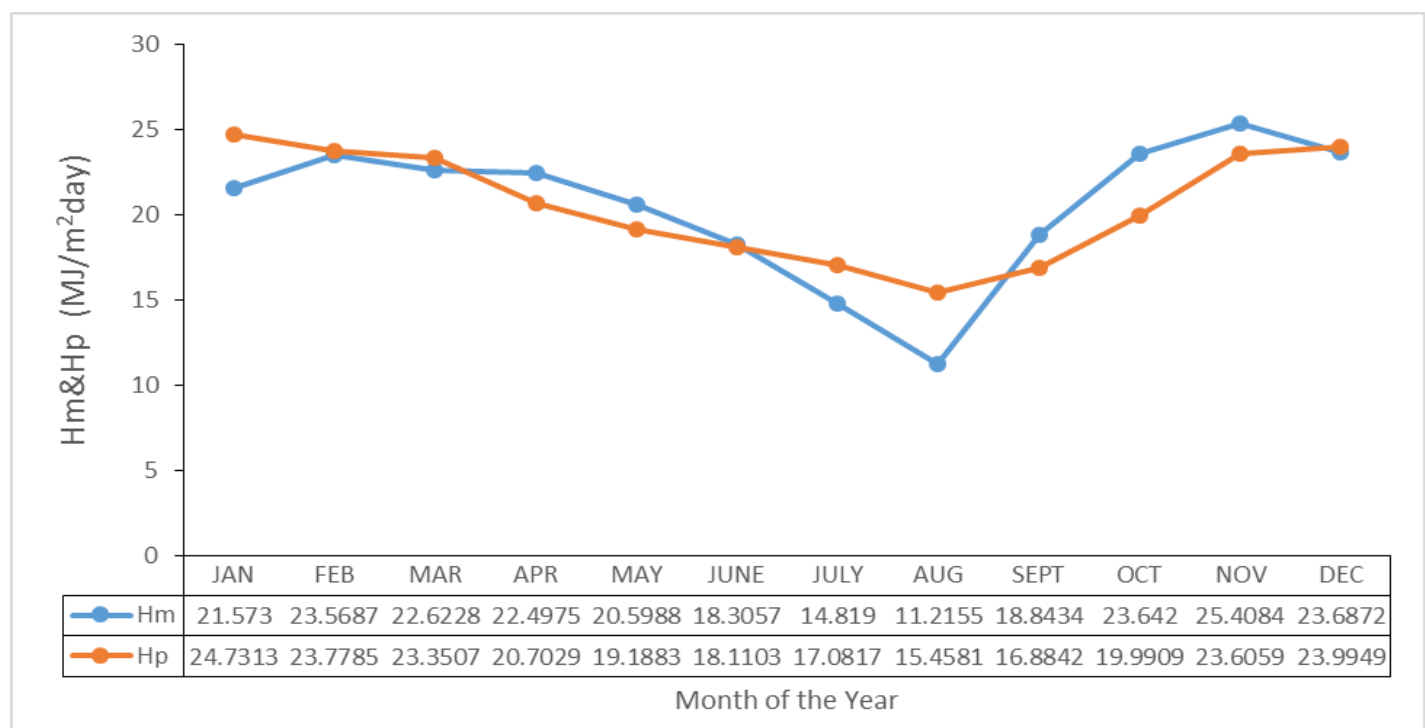

Figure 1: Comparison between measured and predicted monthly mean average global solar radiation for model 1 (2005-2014).

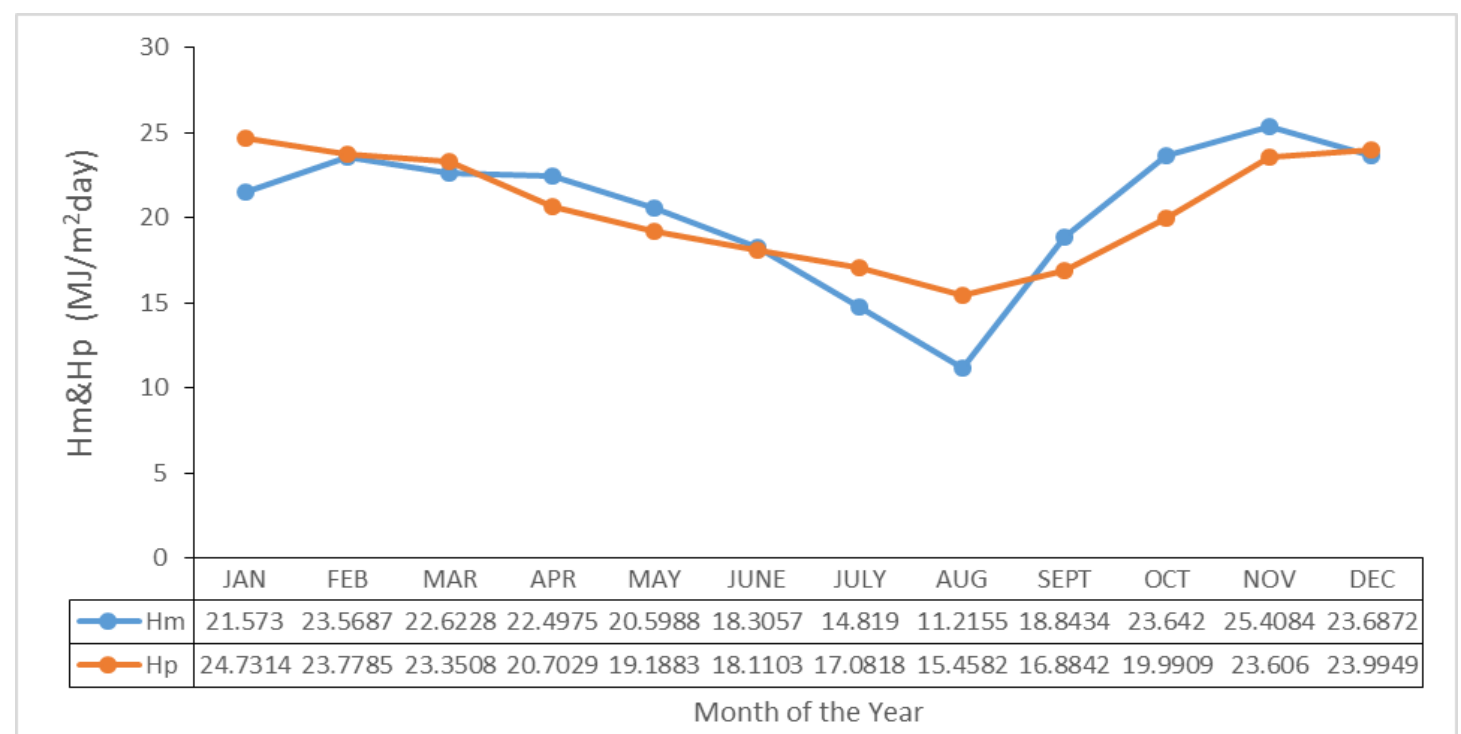

Figure 2: Comparison between measured and predicted monthly mean average global solar radiation for model 2 (2005-2014). 


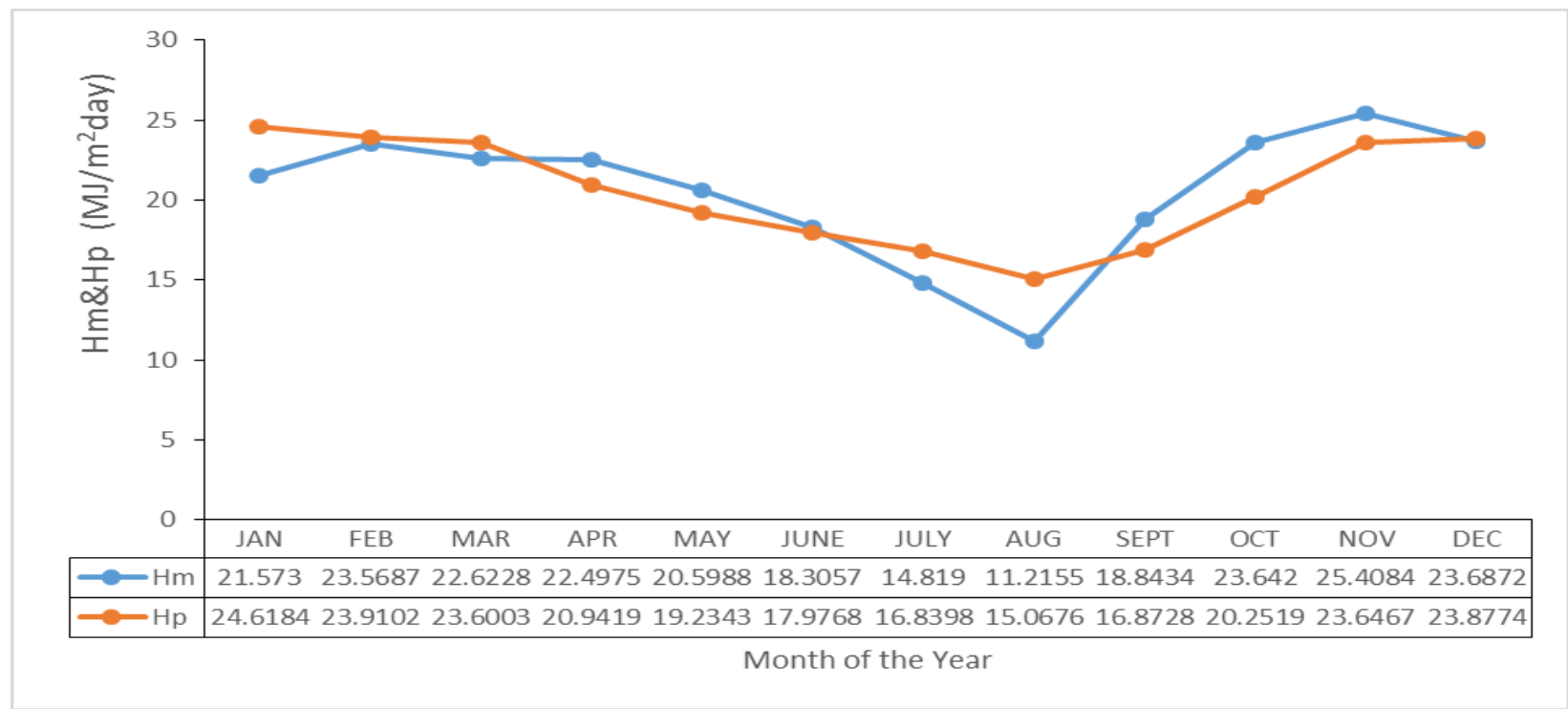

Figure 3: Comparison between measured and predicted monthly mean average global Solar radiation for model 3 (2005-2014).

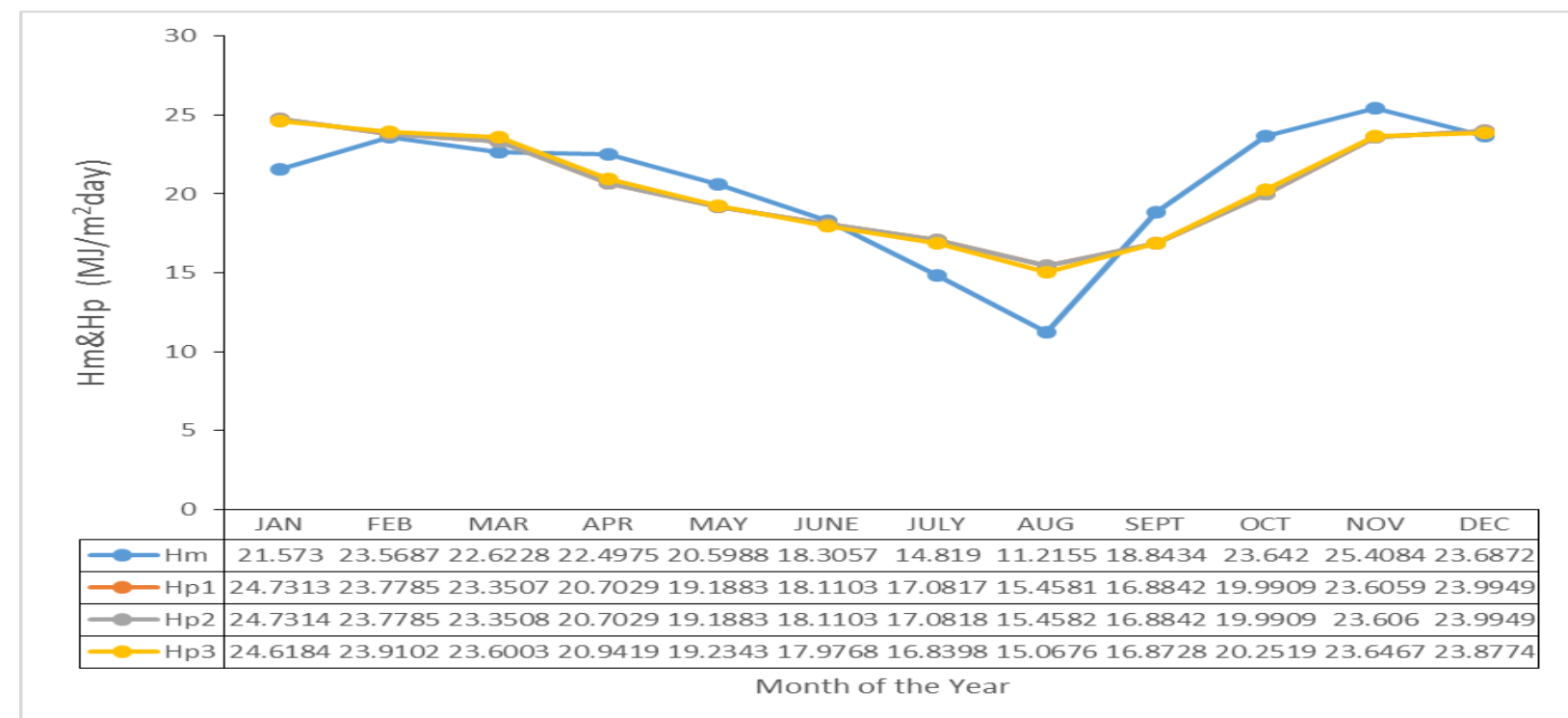

Figure 4: Comparison between measured and predicted monthly mean average global solar radiation for the combine models 1 to 3 (2005-2014

Figures 1 to Figure 4 above clearly shows that the point at which the global solar radiation achieves its highest level was observed during November. This is a clear evidence that the state of atmosphere and sky in Sokoto was very clear. On the other hand, August was studied to be the month in which the global solar radiation obtains a very low level because the sky was very cloudy and not cleared. On the same figure during the dry season, it clearly shows that it reaches the highest level in December, and it reaches a very low level in January as a result of the cold season and dust particles that threw the solar radiation. However, it is manifestly seen that both the measured and predicted global solar radiation are closely related in February, June and December in which April, May September, October, and November acted under measured values while January, July to August behaved above-measured values which happen as a result of changes of atmospheric parameters during measurement. However, there is a similarity in trends of the graph between measured and predicted values of the monthly global solar radiation. 


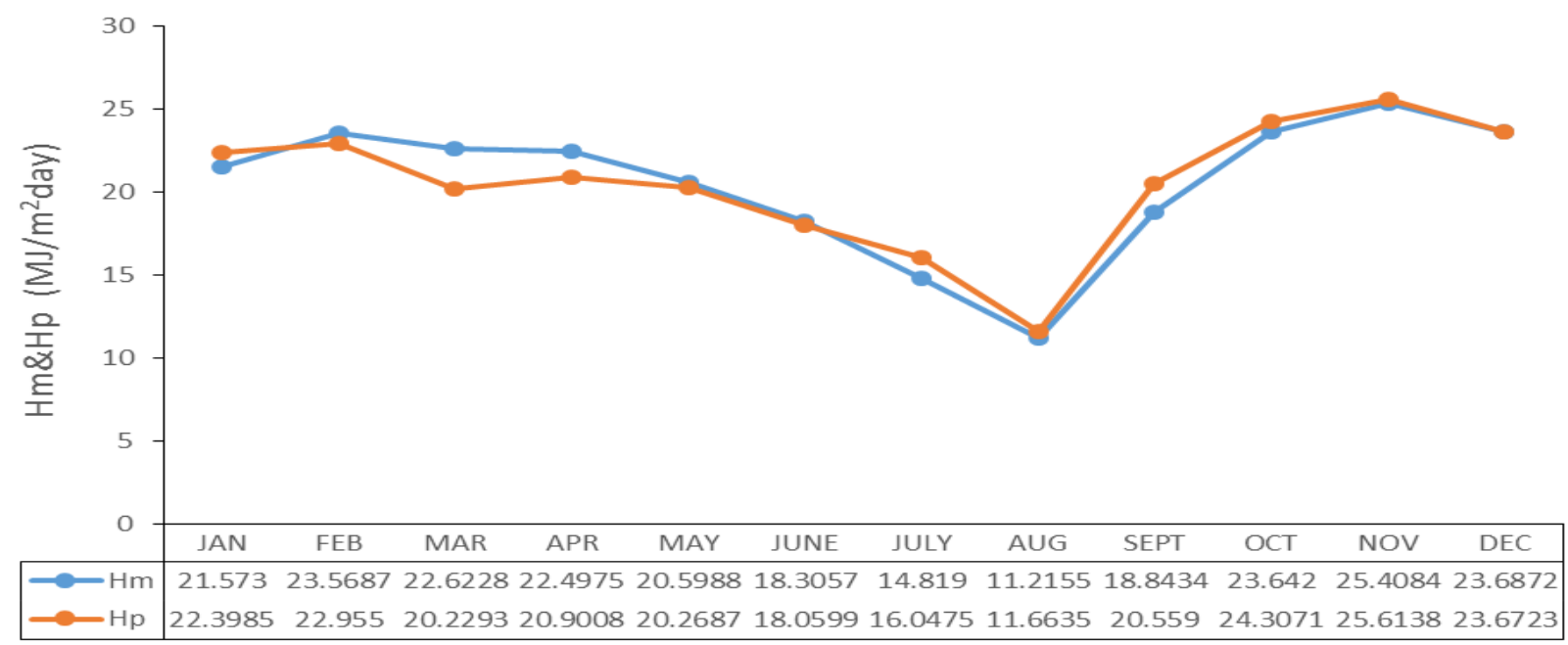

Month of the Year

Figure 5: Comparison between measured and predicted monthly mean average global solar radiation for model 4 (2005-2014).

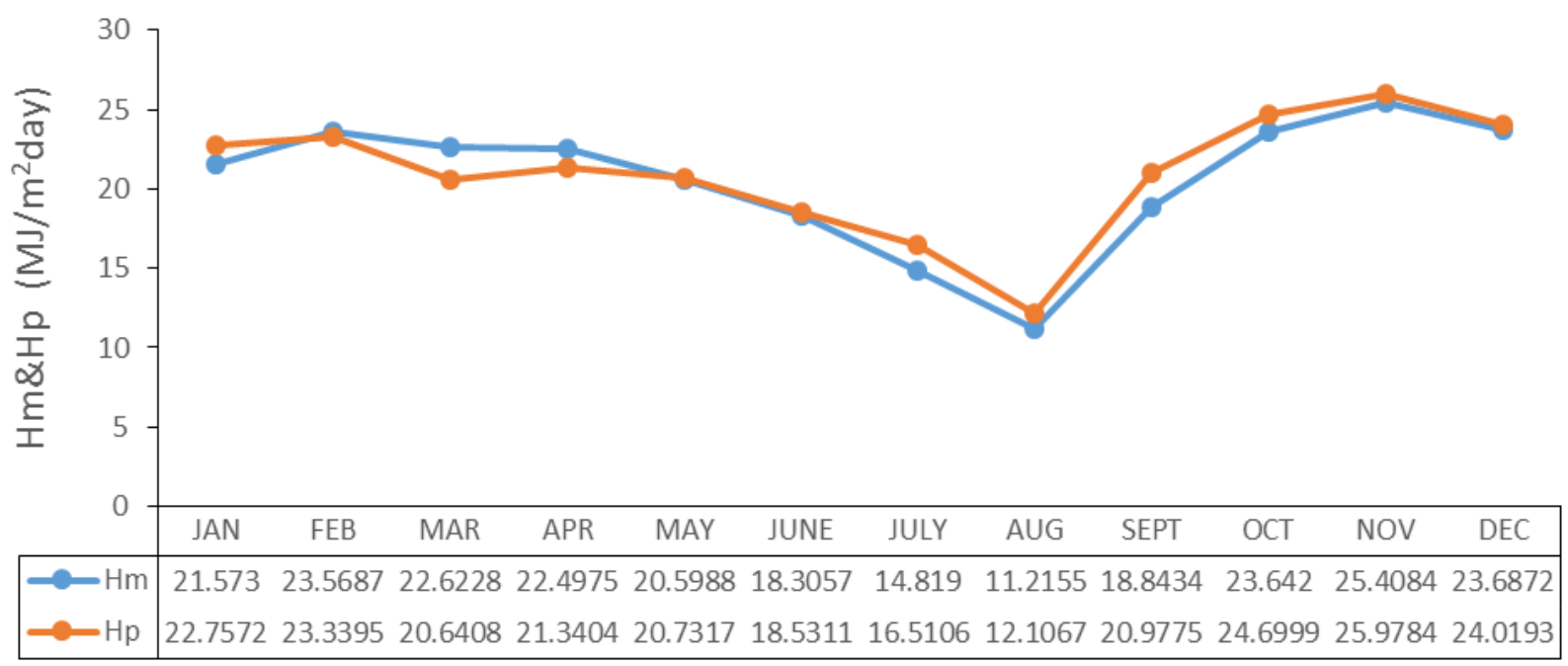

Month of the Year

Figure 6: Comparison between measured and predicted monthly mean average global solar radiation for model 5 (2004-2014).

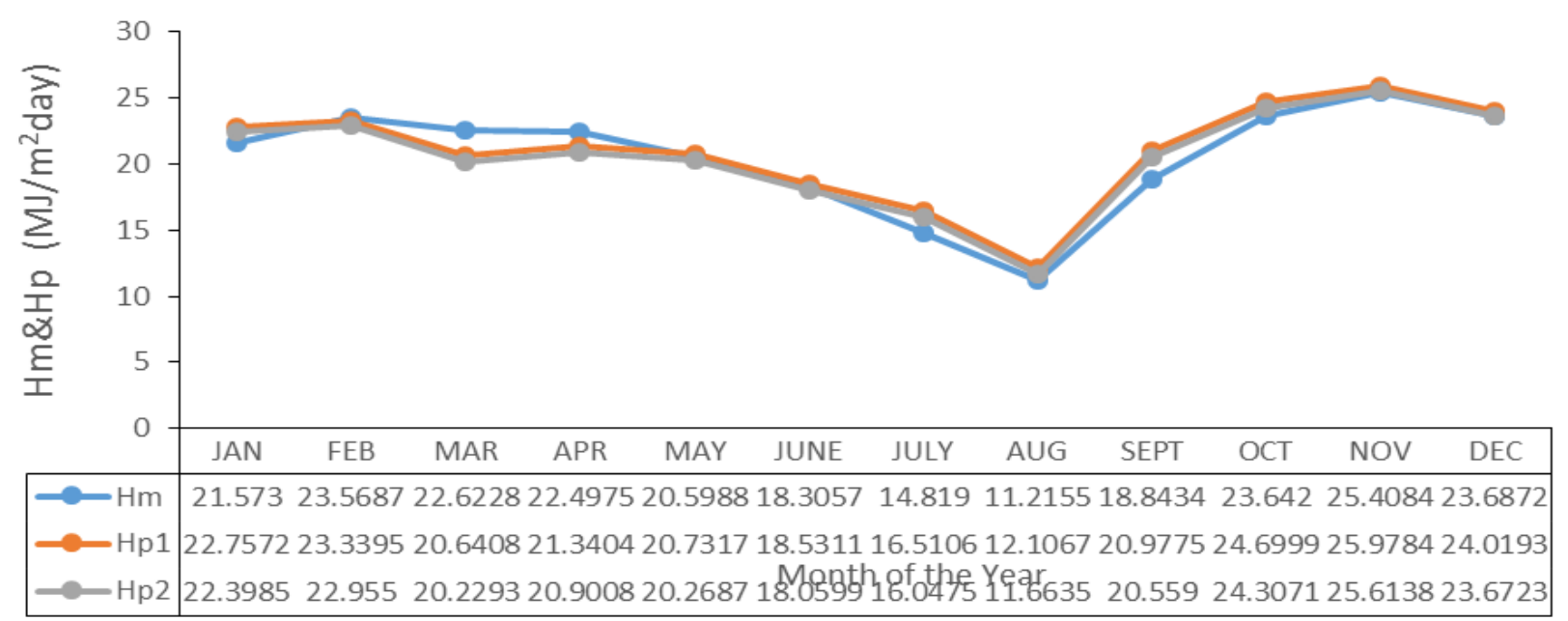

Figure 7: Comparison between measured and predicted monthly mean average global solar radiation for the combine models 4 and 5 (2005-2014). 
Figure (5) to figure (7) above clearly shows that the point at which the global solar radiation reaches its highest level was observed to be in November. This is a clear indication that the state of the atmosphere and the sky in Sokoto was very clear. On the other hand, August was observed to be the month in which the global solar radiation reaches a very low level because the sky was very cloudy and not cleared. On the same figure during the dry season, it clearly shows that it reaches a very low level in December and January as a result of the season and dust particles that threw the solar radiation. However, it is also clearly observed that, both the measured and predicted global solar radiations are closely connected to each other, in which March and April behaved under the measured values while July and September behaved above measured values as a result of changes in atmospheric parameters during measurement. Nevertheless, there is a close similarity between measured and predicted values of monthly mean average global solar radiation.

\section{CONCLUSION}

In this study, firstly, solar radiation models for predicting the monthly global solar radiation on the horizontal surface are reviewed. Then, data of monthly average global solar radiations are analyzed from 2005-2014 for Sokoto state. Empirical correlations are developed to estimate the monthly average global solar radiation on a horizontal surface for Sokoto state. Five new models were developed for estimating the monthly average global solar radiation of Sokoto state. The developed models were tested by calculating the statistical errors namely: RMSE, MBE, MPE, and TStatistics. Based on the values of the standard error (SE), the coefficient of determination $\left(\mathrm{R}^{2}\right)$ and least RMSE value observed, Sunshine Hour's based models gave a better correlation. Therefore, it is found to be that, models $4 \& 5$ are good for predicting the monthly average global solar radiation in Sokoto state the values of the SE, R2, MBE, RMSE, MPE, and t-Statistics for model 4 are: $0.07,1,-0.0088,1.1047,0.4623$ and 0.0267 and for model 5 are: $0.05,0.962,0.4042,1.1746$, 2.608 , and 1.2157 respectively. These models will provide vital information for designers and engineers of solar energy and other renewable-energy devices in this area.

\section{REFERENCES}

[1] D. Vecan, "Measurement and Comparison of solar radiation estimation models for Izmir, Turkey," Izmir Institute of Technology, Turkey, 2011.

[2] John D. and W. A. Beckman, Solar Engineering of Thermal Processes 2nd ed. New York: John Wiley, 1980.

[3] A. Muhammad and T. H. Darma, "Estimation of Global Solar Radiation for Kano State Nigeria Based on Meteorological Data," IOSR-JAP, vol. 6, pp. 19-23, 2014.

[4] G. N. Okonkwo and Nwokoye A. O. C., "Analysis of Solar Energy Parameters in Bida, Nigeria," European scientific journal, vol. 10, pp. 116-130.

[5] El-Sebaii, "Estimation of global solar radiation on horizontal surface in Jeddah, Saudi Arabia," Energy Policy, vol. 37, pp. 3649-3654, 2009.

[6] A.G. Aliyu and A.S. Sambo, Development of a model for computing the total component of solar radiation in Sokoto, Nig. J. Ren. Energy, 2 (2), 10 17, 1991.

[7] Griffin Salima and G. M. S. Chavula, "Determining Angstrom Constant for Estimating Solar Radiation in Malawi," International Journal of Geosciences, vol. 3, pp. 391-397, 2012

[8] J. Almorox, C. Hontoria and M. Benito, "Models for obtaining daily global solar radiation with measured air temperature, Spain," Applied Energy, vol. 88(5), pp. 1703-1709, 2011.

[9] B. Aksoy, "Estimated monthly averaged global solar radiation for Turkey and its comparison with observations," Renewable Energy, vol. 10, pp. 625-633, 1997.

[10] I.T. Togrul, Estimation of solar radiation from Angstroms coefficients by using geographical and meteorological data in Bishkek, Kyrgyzstan, J. Therm. Sc. Tech., 29 (2), 99 - 108, 2009.

[11] Hauwa Muhammad Mavi, "On the use of empirical models for the correlation of global solar radiation with meteorological data for Maiduguri, Nigeria," Bayero University Kano, Kano, 2014.

[12] Okwonko G. N. and Nwokoye A.O.C, "Development of Models for Predicting Global Solar Radiation in Minna, Nigeria using Meteorological Data," IOSR-JAP, vol. 6, pp. 01-06, (May-Jun. 2014).

[13] E.J. Bala, Analysis of some meteorological data for four cities in the North Western Zone of Nigeria, Nig. J. Ren. Energy9 (1\&2), 37 - 41, 2001. 